University of Wollongong

Research Online

Faculty of Engineering - Papers (Archive)

Faculty of Engineering and Information

Sciences

2007

\title{
An investigation into behaviour of electroactive polymers as mechanical sensors
}

G. Alici

University of Wollongong, gursel@uow.edu.au

Geoffrey M. Spinks

University of Wollongong, gspinks@uow.edu.au

J. D. Madden

University of British Columbia, Canada

Y. Wu

University of Wollongong, yanzhe_wu@uow.edu.au

G G. Wallace

University of Wollongong, gwallace@uow.edu.au

Follow this and additional works at: https://ro.uow.edu.au/engpapers

Part of the Engineering Commons

https://ro.uow.edu.au/engpapers/447

\section{Recommended Citation}

Alici, G.; Spinks, Geoffrey M.; Madden, J. D.; Wu, Y.; and Wallace, G G.: An investigation into behaviour of electroactive polymers as mechanical sensors 2007.

https://ro.uow.edu.au/engpapers/447

Research Online is the open access institutional repository for the University of Wollongong. For further information contact the UOW Library: research-pubs@uow.edu.au 


\title{
An Investigation into Behaviour of Electroactive Polymers as Mechanical Sensors
}

\author{
Gursel Alici ${ }^{1}$, Geoffrey M. Spinks ${ }^{1}$, John D. W. Madden², Yanzhe $\mathrm{Wu}^{1}$ and Gordon G. Wallace ${ }^{1}$ \\ ${ }^{1}$ University of Wollongong, ARC Centre of Excellence for Electromaterials Science, Australia, \\ ${ }^{2}$ University of British Columbia, Canada
}

\begin{abstract}
We present our experimental investigation into 'mechanochemoelectrical' behavior of tri-layer polypyrrole (PPy) -type conducting polymer sensors. One end of the polymer strip is clamped and the other-free end-is excited through a mechanical lever system, which provides sinusoidal displacement inputs. The voltage generated and current passing between the two outer PPy layers as a result of the displacement input is measured to model the output/input behaviour of the sensors through their experimental current/displacement and voltage/displacement frequency responses. We specifically targeted the low frequency behaviour of the sensor as it is a relatively slow system. Experimental transfer function models are generated for three sensors with the dimensions of $(7.5 \mathrm{~mm} \times 1 \mathrm{~mm} \times 0.17 \mathrm{~mm}),(10 \mathrm{~mm} \times 1 \mathrm{~mm} \times 0.17 \mathrm{~mm})$, and $(12.5$ $\mathbf{m m} \times 1 \mathrm{~mm} \times 0.17 \mathrm{~mm})$. These models are for use in understanding the dynamic behaviour and sensing ability of the polymers as mechanical sensors. The effect of the active sensor length on the voltage and current outputs are investigated that the shorter is the sensor length, the higher are the voltage output and the current passed. Also, their current and voltage responses under an impulse stimulus (i.e. displacement) are experimentally measured to show their dynamic sensing response.
\end{abstract}

Index Terms - conducting polymer sensors and actuators, system identification/characterisation.

\section{INTRODUCTION}

$\mathrm{A}^{\mathrm{s}}$ s potential electromechanical actuators and sensors, which are very suitable for miniaturization, conducting polymers have attracted the attention of many researchers in the last decade. In a common configuration, they have a composite structure with polymer layers separated from each other with an ionically conductive but electronically insulating film. When the right stimulus, which is usually a very small voltage -typically $1 \mathrm{~V}$, or a current, is applied to the polymer layers, a volume expansion and contraction occurs due to electro-chemo-mechanical properties of the polymers. The change in the volume generates a bending displacement -- the electrochemical energy is converted into mechanical energy. As a result, a considerable amount of research has been devoted to modeling and understanding their behaviours in order to improve their synthesis conditions such that they can be reliable actuators and sensors for new applications ranging from biomedical devices to micromanipulators.

Footnote
In this paper, we present experimental frequency response and impulse results and their implications for polypyrrole (PPy) based tri-layer conducting polymer sensors, which operate in a non-aqueous medium, i.e., air, as opposed to their predecessors. A mechanical stimulus such as a displacement is applied to the free end of the sensor. This makes the top layer of the sensors in tension and the bottom layer in compression such that while the electrolyte ions will enter the upper polymer layer, they will leave lower layer polymer. This is analogous to applying a potential difference to the polymer structure such that the upper layer expands as a result of the transfer of the ions from the insulating electrolyte film into it, the lower layer contracts as a result of losing ions. The movement of the ions or electron holes in and out of the polymer layers generates electric current. The experimental results presented in this study suggest that the resistance of the polymer sensors decreases until $2 \mathrm{~Hz}$ and after which it increases such that the current passed decreases sharply after $2 \mathrm{~Hz}$ irrespective of the actuator lengths tested. It must be noted that the thickness of the polymer layers of the three sensors studied was the same, i.e. $30 \mu \mathrm{m}$. In our previous work on polymer actuators [1-7], we had aimed to establish lumpedparameter mathematical models and their experimental validation in order to characterize the actuators' behaviour and exploit these behaviours in useful applications. We made a two-finger robotic gripper to manipulate objects as heavy as 50 times the total mass of the polymer actuators used [6]. This study is the extension of our continuing efforts to understand the behaviour of the polymer actuators and sensors and pave the way towards more functional devices. Although significant amount of work has been dedicated to modeling, analysis and characterization of conducting polymer actuators, little has been devoted to the conducting polymers as mechanical sensors. While polymer actuators convert the electrical energy into the mechanical energy, they do the opposite when they are used as sensors. The polymer backbone is like a porous structure filled with ions. The unbalanced charge distribution in the polymer layers is dominated by the movement of dopant ions. As soon as a mechanical input such as a displacement is applied, the dopant ion concentration in the polymer layers changes temporarily and hence generates a potential difference across the sensor strip. The influence of the sensor length on the voltage and current frequency responses are studied. The results are new in the sense that the mechanism behind the operation of polymer actuators and sensors is further elaborated through the frequency response results. Based on the results, the transfer function of the sensors can be 
established for subsequent use in analyzing and designing feedback control systems for conducting polymer actuators and sensors.

The work most relevant to this study includes that of Takashima et al. [8] and $\mathrm{Wu}$ [9]. Takashima et al. [8] reported on the mechanically induced current observed in polyaniline films under a tensile load, without considering the effect of dopant ions. The mechanism behind this 'mechanochemoelectrical' behaviour is said to be the stretching of the film which changes the polymer density and hence induces a redox current. The induced charge is proportional to the axial stress applied to the film. Wu [9] has investigated the same type of PPy tri-layer sensor described in the present work. $\mathrm{Wu}$ reported that the polarity and magnitude of the voltage generated under a mechanical input depend on the size of dopant ions. The small mobile dopant such as $\mathrm{ClO}_{4}^{-}$and the large immobile DBS dopant have produced negative (out of phase) and positive (in phase) voltages, respectively. Furthermore, the potentiostatic mode (current output) is more sensitive than the galvanostatic mode (voltage output) to employ the polymer as a displacement sensor. This is in agreement with the fact that while conducting polymers are excellent charge generators, they produce low voltages, as opposed to piezoelectric materials/ generators [10].

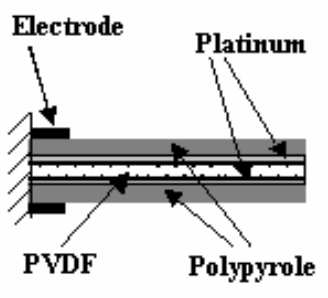

(a)

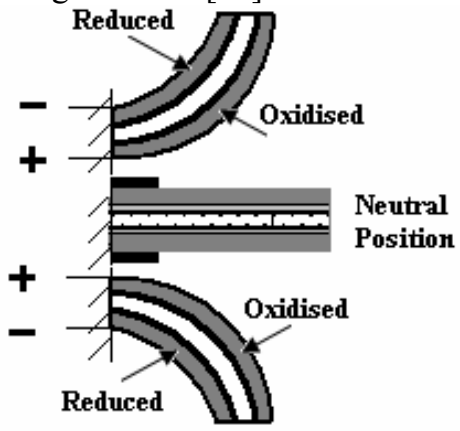

(b)
Fig. 1. (a) Schematic structure of the conducting polymer sensor/actuator, and (b) Schematic representation of the bending principle.

\section{Description of Polymer SEnSOR}

The structure of the polymer sensor considered in this study is shown in Fig. 1. The sensor has five layers. The outmost two layers which are polypyrrole with the thicknesses of $30 \mu \mathrm{m}$ are the electroactive elements providing actuation or sensing. The middle layer is polyvinylidine fluoride (PVDF) with a thickness of $110 \mu \mathrm{m}$, an inert, nonconductive, porous polymer. It serves as a separator for the two PPy layers and the reservoir for electrolyte $\quad \mathrm{TBA}^{\mathrm{P} \mathrm{PF}_{6}}$ (tetrabutylammonium hexafluorophosphate) $0.05 \mathrm{M}$ in solvent propylene carbonate. The electrolyte and the solvent need to be stored in the PVDF layer in order to operate the sensor/actuator in air. Otherwise, it has to be operated in an aqueous medium consisting of the electrolyte and the solvent. Thin layers of platinum of 10 to $100 \AA$ are sputter-coated on both sides of PVDF to enhance the conductivity between PPy layers and the electrolyte. A schematic comparison of a polymer actuator and a sensor is provided in Fig. 2.

\section{EXPERIMENTAL EVALUATION AND RESULTS}

The experimental system is provided in Figs. 3 and 4, where the input is provided by a mechanical lever system and the output voltage and current are recorded separately to obtain Current/Displacement and Voltage/Displacement responses in the frequency domain.
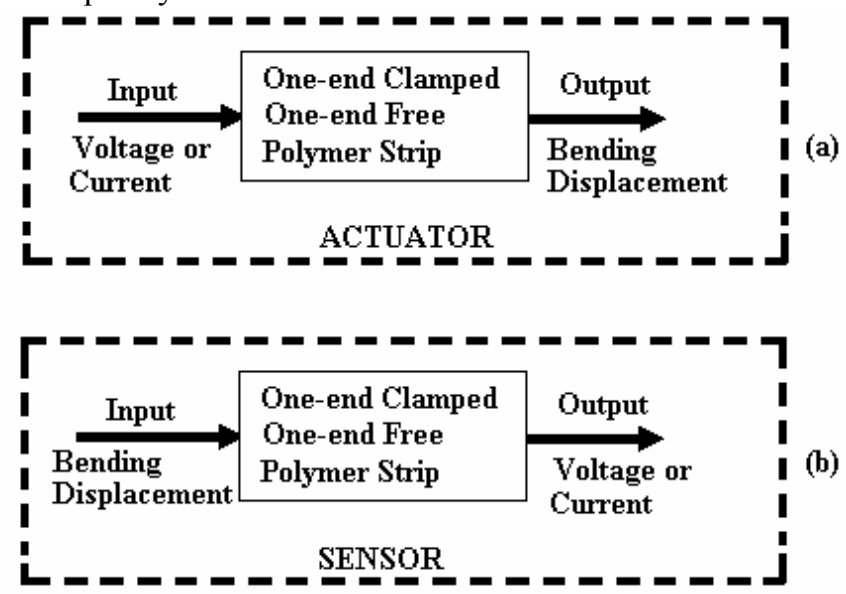

Fig. 2. Comparison of the conducting polymer actuators and sensors.

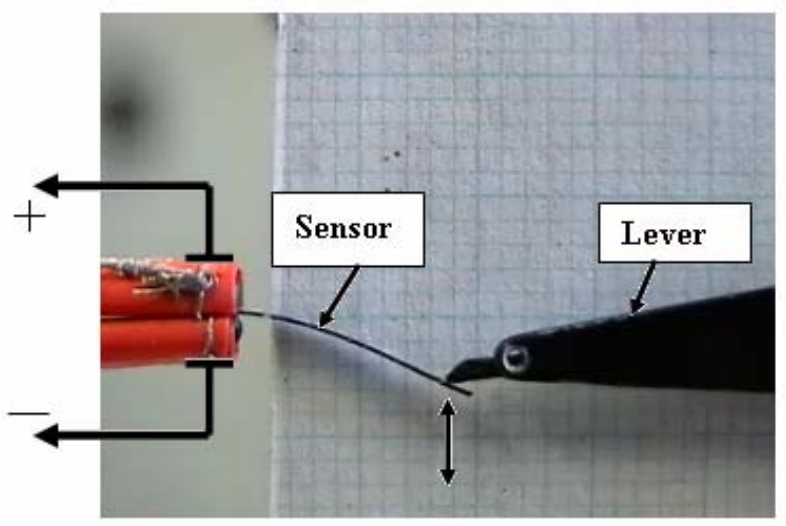

Fig. 3. Configuration of the lever and sensor.

As shown in Fig.4, a dual-mode lever arm system (Model 300B-LR, Aurora Scientific Inc.) is used to provide the input displacement. The induced electrical signals (voltage and current) in the sensor due to mechanical stimulation are conditioned with an $e D A Q$ Potentiostat, a three-electrode preamplifier. The signals to be measured are connected to the inputs of the $e D A Q$ e-corder unit, which is interfaced with a $\mathrm{PC}$ for data acquisition.

For the three sensors with the dimensions of $(7.5,10,12.5 \mathrm{~mm}$ x $1 \mathrm{~mm} \times 0.17 \mathrm{~mm}$ ), frequency response experiments were conducted under sinusoidal inputs with the amplitude of \pm 1 $\mathrm{mm}$ and frequencies ranging from $0.01 \mathrm{~Hz}$ to $20 \mathrm{~Hz}$. The frequency steps are presented in Table 1. A special attention has been devoted to the low frequency behaviour of the sensor. 


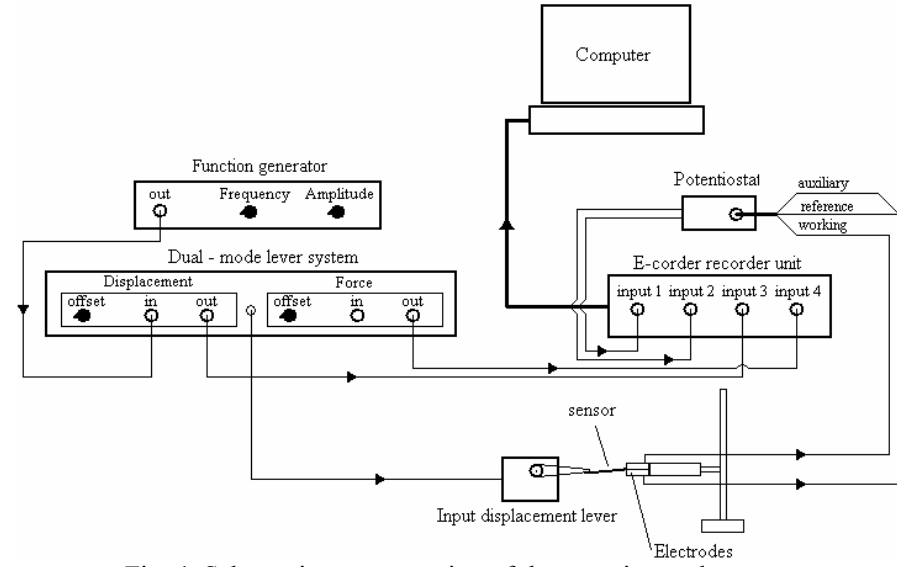

Fig. 4. Schematic representation of the experimental setup.

A biased displacement of $2 \mathrm{~mm}$ was applied to the actuator/sensor to keep it in contact with the lever during measurements. Based on the measured response (current and voltage) and the input (displacement) sinusoidal, the magnitude ratio and phase angle are calculated using Eq.1, and Fig. 5. The magnitude ratio and phase angle data are plotted against the frequency, and are presented in Figs 7-12. When a dynamic system is subjected to a sinusoidal input $p(t)$, the steady-state output $x(t)$ of the system is also sinusoidal with a different amplitude and a phase lag/or lead, as schematically presented in Fig. 5(a). With reference to Fig. 5(b), the magnitude ratio and the phase angle are determined from

$$
|\mathbf{G}(\mathbf{j} \omega)|=\frac{\mathbf{A}_{1}}{\mathbf{P}}, \quad \phi=(\omega, \mathrm{rad} / \mathrm{sec}) \delta \mathrm{t}=\operatorname{radian}
$$

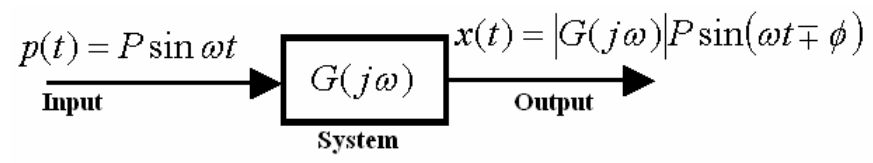

(a)

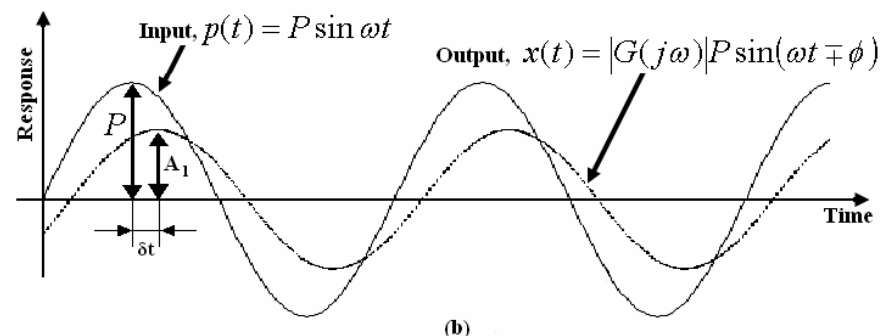

Fig. 5. (a): Schematic representation of the response of a dynamic system under a sinusoidal input (a), (b); the relationship between the input and the response.

Table 1: Amplitude and frequency of the sinusoidal displacement input.

\begin{tabular}{|c|c|}
\hline Amplitude & Frequency $(\mathrm{Hz})$ \\
\hline $\pm 1 \mathrm{~mm}$ & $0.01,0.015,0.02,0.025,0.03,0.035,0.04$ \\
& $0.045,0.05,0.055,0.06,0.065,0.07,0.075$ \\
& $0.08,0.085,0.09,0.095,0.1,0.2,0.3,0.4,0.5$ \\
& $0.6,0.7,0.8,0.9,1,2,3,4,5,6,7,8,9,10,11$ \\
& $12,13,14,15,16,17,18,19,20$ \\
\hline
\end{tabular}

\section{Modelling And Estimation Results}

The output/input behaviour of the sensors has been modeled using the experimental current/displacement and voltage/displacement frequency responses of the sensors. Assume that the transfer functions to be identified are in the form of:

$$
\mathbf{G}(\mathbf{s})=\frac{\mathbf{B}(\mathbf{s})}{\mathbf{A}(\mathbf{s})}=\frac{\mathbf{b}_{\mathbf{n}} \mathbf{s}^{\mathbf{n}-1}+\mathbf{b}_{\mathbf{n}-1} \mathbf{s}^{\mathbf{n}-2}+\ldots+\mathbf{b}_{1}}{\mathbf{s}^{\mathbf{m}}+\mathbf{a}_{\mathbf{m}} \mathbf{s}^{\mathbf{m}-1}+\ldots+\mathbf{a}_{1}}, \mathbf{m}>\mathbf{n}
$$

The transfer function, whose coefficients will be estimated using the experimental transfer function $\mathbf{G}_{\exp }(\mathbf{j} \boldsymbol{j})$, is described by

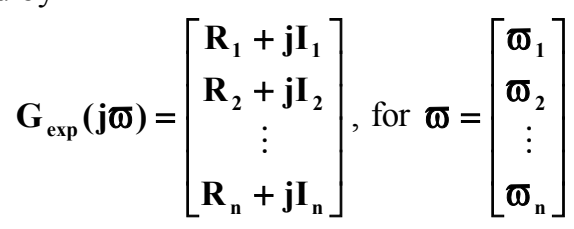

From the equivalence of the theoretical and experimental transfer functions described by Eqs. 2 and 3, we obtain

$$
\begin{gathered}
\frac{b_{n}\left(j \varpi_{1}\right)^{n-1}+b_{n-1}\left(j \varpi_{1}\right)^{n-2}+\ldots+b_{1}}{\left(j \varpi_{1}\right)^{m}+a_{m}\left(j \varpi_{1}\right)^{m-1}+\ldots+a_{1}}=R_{1}+j I_{1} \\
\frac{b_{n}\left(j \varpi_{2}\right)^{n-1}+b_{n-1}\left(j \varpi_{2}\right)^{n-2}+\ldots+b_{1}}{\left(j \varpi_{2}\right)^{m}+a_{m}\left(j \varpi_{2}\right)^{m-1}+\ldots+a_{1}}=R_{2}+j I_{2} \\
\vdots \\
\frac{b_{n}\left(j \varpi_{n}\right)^{n-1}+b_{n-1}\left(j \varpi_{n}\right)^{n-2}+\ldots+b_{1}}{\left(j \varpi_{n}\right)^{m}+a_{m}\left(j \varpi_{n}\right)^{m-1}+\ldots+a_{1}}=R_{n}+j I_{n}
\end{gathered}
$$

Eq.4 can be re-written in a matrix-vector form including a vector of the unknown coefficients, which can be determined using a classical least squares estimation method.

$$
\begin{aligned}
& \mathbf{P}\left(\left[\varpi_{1}, \Phi_{2}, \ldots, \Phi_{\mathrm{n}}\right]\left[\mathbf{R}_{1}, \mathbf{I}_{1}, \mathbf{R}_{2}, \mathbf{I}_{2}, \ldots, \mathbf{R}_{\mathrm{n}}, \mathbf{I}_{\mathrm{n}}\right]\right]\left[\begin{array}{c}
\mathbf{b}_{1} \\
\mathbf{b}_{2} \\
\vdots \\
\mathbf{b}_{\mathbf{n}} \\
\mathbf{a}_{1} \\
\mathbf{a}_{2} \\
\vdots \\
\mathbf{a}_{\mathrm{m}}
\end{array}\right]= \\
& \mathbf{Q}\left(\left[\varpi_{1}, \Phi_{2}, \ldots, \Phi_{\mathrm{n}}\right]\left[\mathbf{R}_{1}, \mathbf{I}_{1}, \mathbf{R}_{2}, \mathbf{I}_{2}, \ldots, \mathbf{R}_{\mathrm{n}}, \mathbf{I}_{\mathrm{n}}\right]\right)
\end{aligned}
$$

This transfer function estimation can be accomplished using Output Error (OE) model estimation in MATLAB Identification Toolbox. The structure of the OE model is depicted in Fig. 6, where the main advantage is that if the input-output data is collected for a system operating without feedback control, the Fourier transform techniques can extract only the relevant frequency content, and a correct description 
of the transfer function $G(s)=B(s) / A(s)$ is obtained regardless of the nature of the disturbance [11].

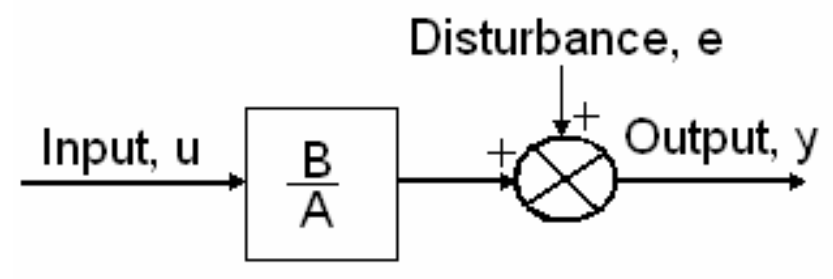

Fig. 6. The structure of the OE model.

\section{A. Estimated Transfer Functions}

The experimental and estimated magnitude and phase plots for the three sensors with the dimensions of $(7.5 \mathrm{~mm} \times 1 \mathrm{~mm} \times 0.17$ $\mathrm{mm}), \quad(10 \mathrm{~mm} \times 1 \mathrm{~mm} \times 0.17 \mathrm{~mm})$, and $(12.5 \mathrm{~mm} \times 1 \mathrm{~mm} \times 0.17$ $\mathrm{mm})$ are depicted in Figs. 7-12. The identified transfer functions are provided in Table 2.
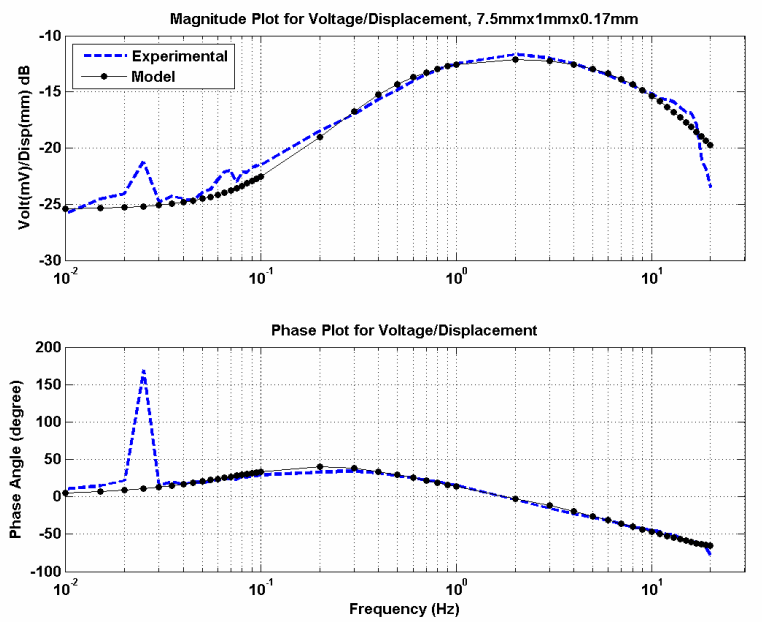

Fig. 7. The estimated and experimental Voltage/Displacement frequency response of the sensor with the dimensions of $(7.5 \mathrm{~mm} \times 1 \times 0.17 \mathrm{~mm})$.

Table 2: Summary of the estimated transfer functions for the $7.5 \mathrm{~mm}, 10 \mathrm{~mm}$, $12.5 \mathrm{~mm}$ sensors in length in the second, third and fourth rows, respectively.

\begin{tabular}{|c|c|}
\hline $\begin{array}{c}\text { Voltage/Displacement } \\
\text { Transfer Functions }\end{array}$ & $\begin{array}{c}\text { Current/Displacement } \\
\text { Transfer Functions }\end{array}$ \\
\hline $14.15 \frac{\mathrm{s}+0.6144}{(\mathrm{~s}+54)(\mathrm{s}+3.0215)}$ & $16.81 \frac{\mathrm{s}+0.2705}{(\mathrm{~s}+52.295)(\mathrm{s}+2.824)}$ \\
\hline $16.12 \frac{\mathrm{s}+1.2416}{(\mathrm{~s}+\mathbf{7 5 . 3 9 4})(\mathrm{s}+5.132)}$ & $\mathbf{2 1 . 2 3} \frac{\mathrm{s}+0.5142}{(\mathrm{~s}+66.777)(s+3.898)}$ \\
\hline $\mathbf{5 . 8 9 2} \frac{\mathrm{s}+\mathbf{0 . 8 7 5}}{(\mathrm{s}+28.059)(\mathrm{s}+3.66)}$ & $10.07 \frac{\mathrm{s}+0.3634}{(\mathrm{~s}+31.313)(s+3.098)}$ \\
\hline
\end{tabular}

The transfer function identified for the sensor $7.5 \mathrm{~mm} \times 1 \mathrm{~mm} \times 0.17 \mathrm{~mm}$ is employed to estimate the voltage output of the sensor at different frequencies, which are shown in Fig. 13. The close correspondence between the experimental and estimated voltage outputs demonstrate that the transfer function is effective enough to estimate electrical output of the sensor. Similar close correspondence has been obtained with experimental current data, which is not provided here for the sake of brevity.
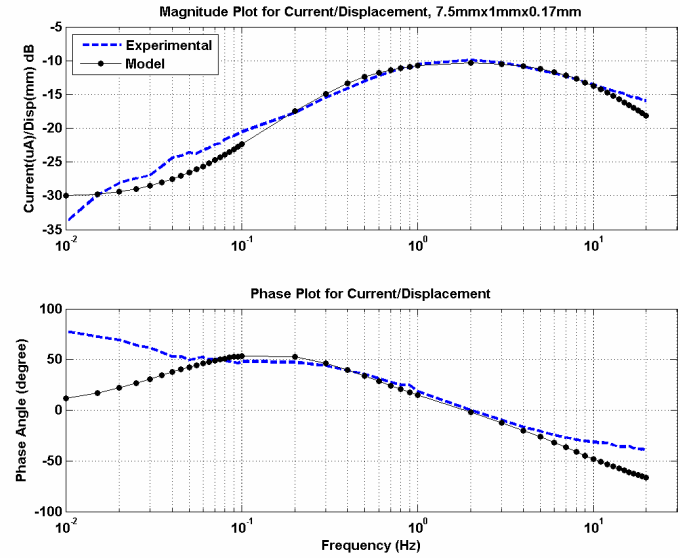

Fig. 8. The estimated and experimental Current/Displacement frequency response of the sensor with the dimensions of $(7.5 \mathrm{~mm} \times 1 \times 0.17 \mathrm{~mm})$.
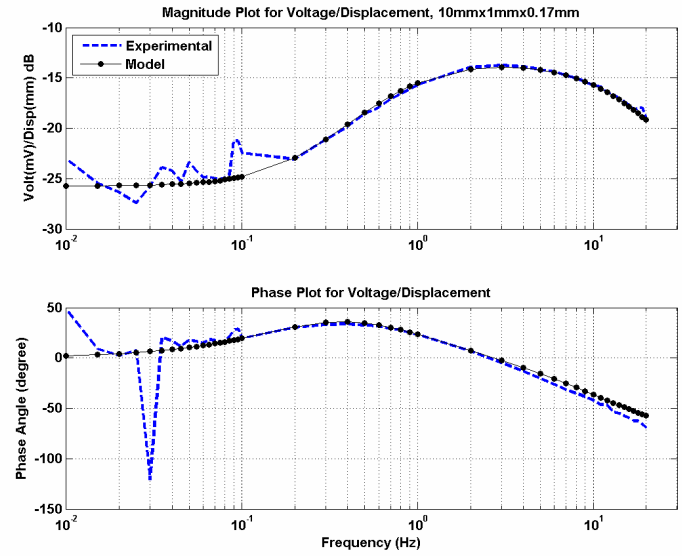

Fig. 9. The estimated and experimental Voltage/Displacement frequency response of the sensor with the dimensions of $(10 \mathrm{~mm} \times 1 \times 0.17 \mathrm{~mm})$.
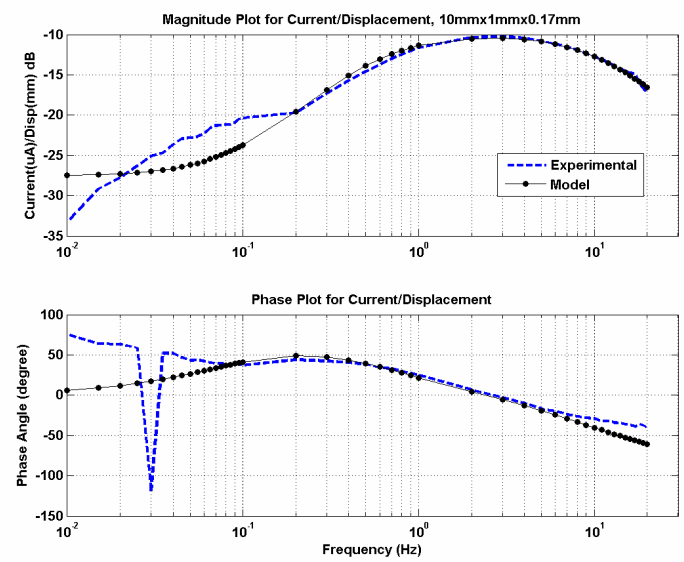

Fig. 10. The estimated and experimental Current/Displacement frequency response of the sensor with the dimensions of $(10 \mathrm{mmx} 1 \times 0.17 \mathrm{~mm})$.

\section{Discussion of Results}

With reference to the frequency response models presented in Figs 7-12, the peak current and voltage occurs at approximately occurs at $2 \mathrm{~Hz}$ for the three sensors considered in this study. However, the results in Figs 7-12 indicate that the shorter is the actuator length, the higher are the magnitudes of the voltage output and the current passing The results presented in this study are in agreement with the finding in the 
literature [1] that the actuation ability of the conducting polymers significantly depends on the polymer layer thickness rather than the length. The current passes as result of movement of ions in and out of the polymer layers when the mechanical stimulus is applied to the sensor. Using the voltage output and current passed by the three sensors, the resistance of the sensors are calculated that the resistance decreases up to $2 \mathrm{~Hz}$ and increases after $2 \mathrm{~Hz}$, as shown in Fig. 14.
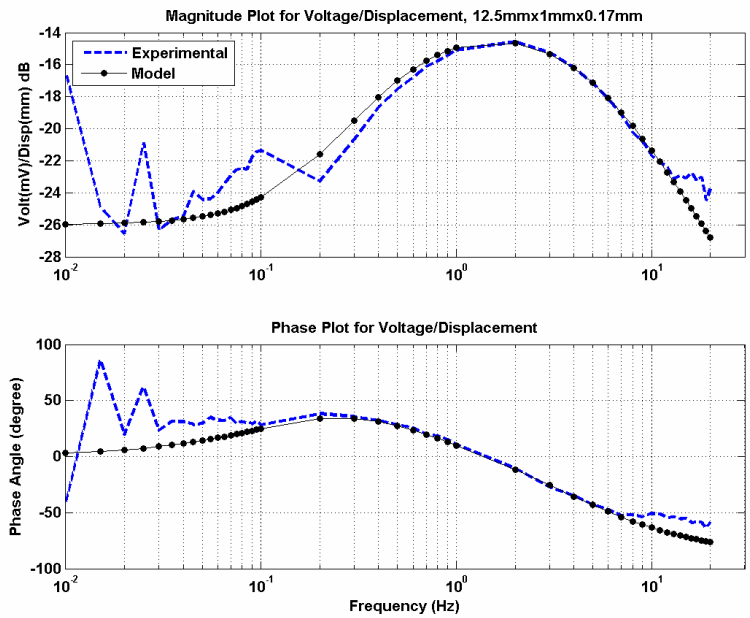

Fig. 11. The estimated and experimental Voltage/Displacement frequency responses of the sensor with the dimensions of $(12.5 \mathrm{mmx} 1 \times 0.17 \mathrm{~mm})$.
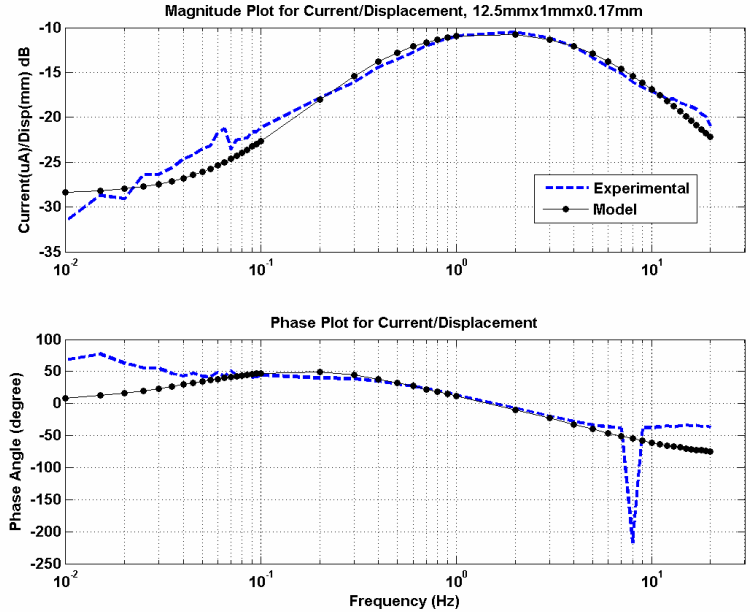

Fig. 12. The estimated and experimental Current/Displacement frequency response of the sensor with the dimensions of $(12.5 \mathrm{mmx} 1 \mathrm{x} 0.17 \mathrm{~mm})$.

The electrical power (volt $\mathrm{x}$ current) generated during the frequency response measurements are calculated for the three sensors. The power results indicate that the shorter is the length, the higher is the power generated, as shown in Fig. 14. We have repeated the frequency response experiments with another sample of polymer sensors with a $2 \mathrm{~mm}$ width and a range of lengths (thickness unchanged), and found that the shorter is the sensor length, the higher are the amplitudes of the voltage output and the current passed, as shown in Fig. 15. This conclusion is also supported by the current and voltage magnitude responses provided in Figs.7-12.

Further, the current and voltage responses of the sensors under an impulse stimulus (i.e. displacement) are experimentally measured for the same samples for a number of times. The results indicate that the dynamic sensing response is quite fast and repeatable; one of the results is shown in Fig.16. We propose to use this experimental impulse response to generate the transfer function models of the sensors, and estimate their bandwidths and other dynamic characteristics, as an alternative method to the frequency response experiments. It must be noted that the impulse responses shown in Fig.16 show an underdamped response as opposed to the transfer functions identified for the results in Figs. 7-12, which indicate an overdamped response. To elaborate the reason for this, we obtained the impulse response of a sensor with $2 \mathrm{~mm}$ width and found that the response shows an overdamped response.
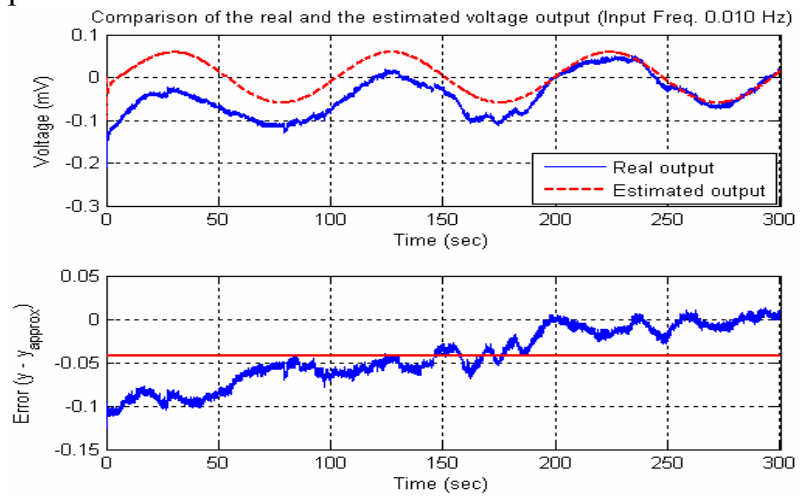

(a)
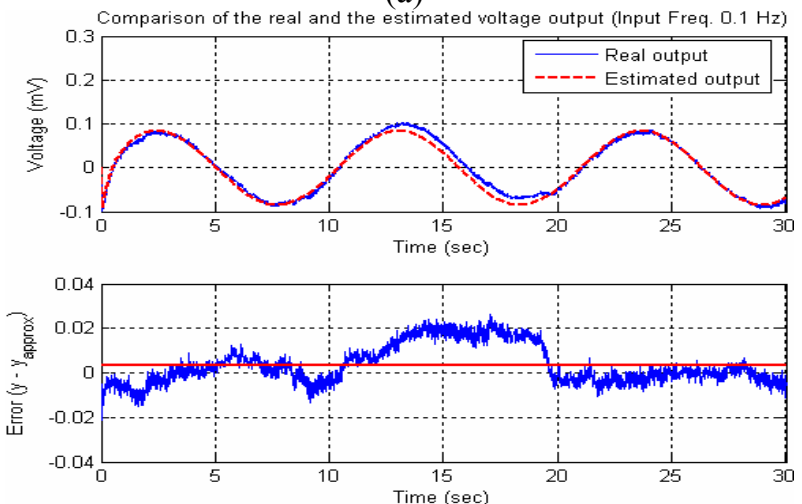

(b)
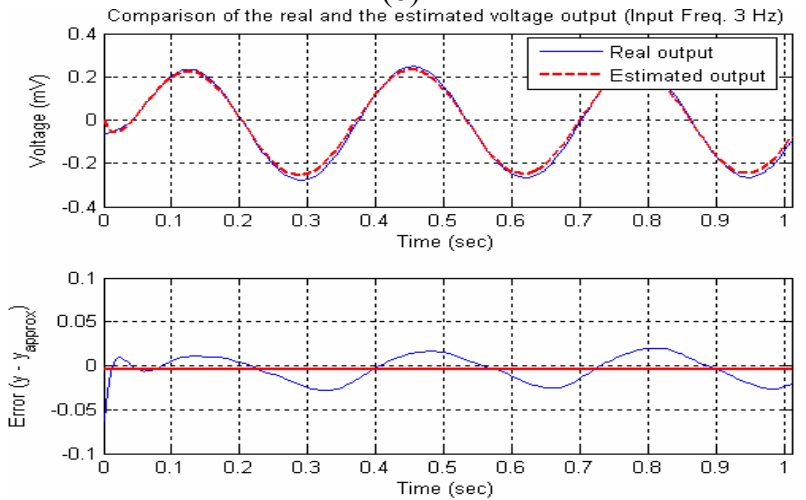

(c)

Fig. 13. Comparison of the experimental and estimated voltage outputs for the sensor $(7.5 \mathrm{~mm} \times 1 \times 0.17 \mathrm{~mm})$ under different input frequencies; (a) $0.01 \mathrm{~Hz}$, (b) $0.1 \mathrm{~Hz}$, and (c) $3 \mathrm{~Hz}$.

An exemplary response is shown in Fig.17. This and other result we cannot provide in this paper suggest that the damping behaviour of the polymer sensors is determined by the width; the higher is the width, the more oscillatory is their 
response. We will report on this issue in detail in another publication.
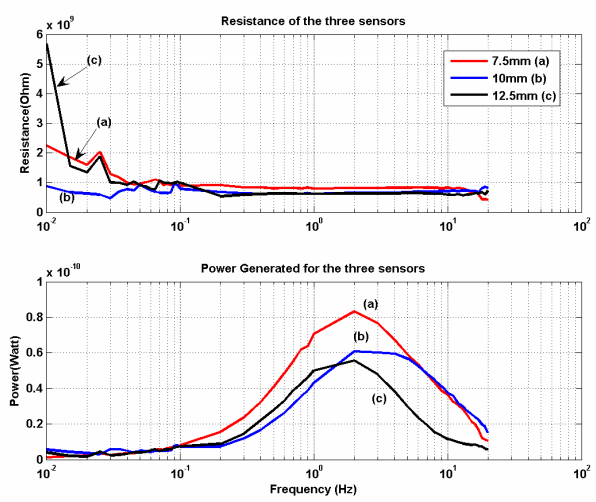

Fig. 14. The resistance (top plot) and the electrical power generated (bottom plot) by the three sensor.
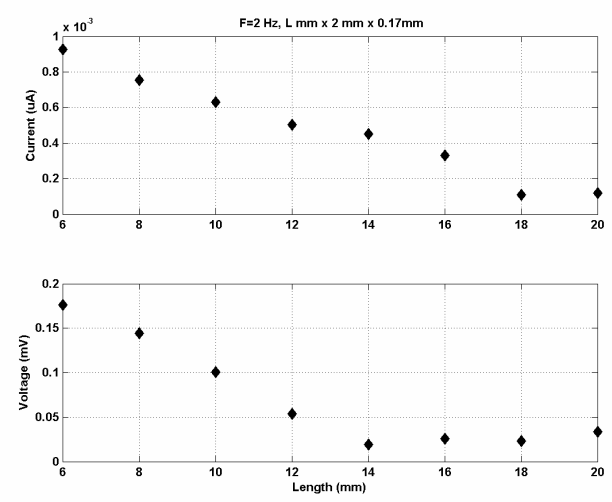

Fig. 15. Variation of the voltage and current output with the active sensor length.
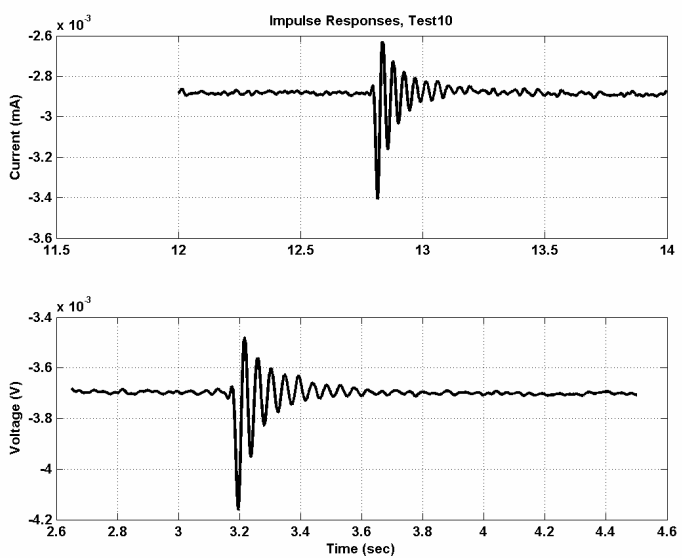

Fig.16. The dynamic electrical sensing response of a $20 \mathrm{~mm} \times 4 \mathrm{~mm} \times 0.17 \mathrm{~mm}$ sensor under an impulse displacement (flicking with a ruler!).

\section{CONCLUSION}

We have presented our experimental investigation into the dynamic behaviour of mechanical polymer sensors in order to draw an analogy between the actuation and sensing abilities of these promising electroactive materials. We have identified the transfer functions describing the electrical outputs of the conducting polymers, which can be used as mechanical displacement and force sensors. The experimental results suggest that the resistance of the polymer structure changes under the mechanical stimulus such that irrespective of the active length of the sensors, the minimum resistance occurs at approximately $2 \mathrm{~Hz}$. The future work includes identifying more descriptive analytical mathematical models, from which we plan to determine analogous electrical circuit models in order to shed more light on the actuation and sensing mechanisms of conducting polymers, and their similarities and differences.

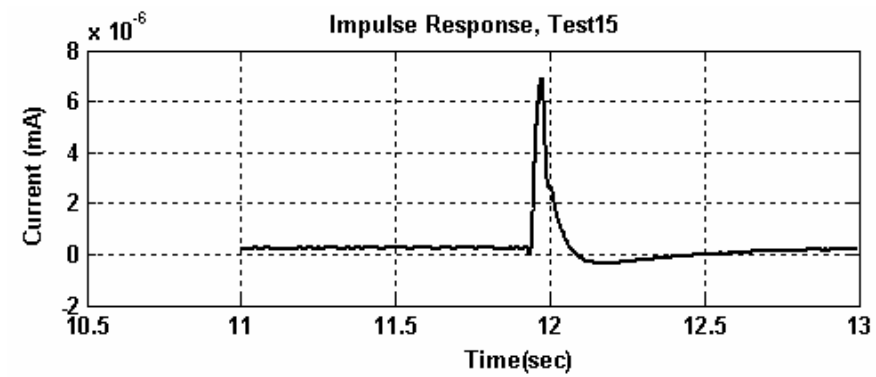

Fig.18. The current response of a $8 \mathrm{~mm} \times 2 \mathrm{~mm} \times 0.17 \mathrm{~mm}$ sensor under an impulse displacement (flicking with a ruler!).

\section{ACKNOWLEDGMENT}

The authors would like to thank the postgraduate students Mr. Nam. H. Huynh and Mr. D. Julian Munoz for their help in collecting experimental data and identifying the transfer functions.

\section{REFERENCES}

[1] G. Alici, P. Metz, and G. M. Spinks, "A Methodology towards Geometry Optimisation of High Performance Polypyrrole (PPy) Actuators", Journal of Smart Materials and Structures, Volume 15, pp. $243-252,2006$.

[2] G. Alici, ,B. Mui, and C. Cook, "Bending Modeling and Its Experimental Verification for Conducting Polymer Actuators Dedicated to Manipulation Applications", Sensors and Actuators A, Volume 126, No.2, pp. 396 - 404, 14 February, 2006.

[3] G. Alici, P. Metz, and G. M. Spinks, "A Mathematical Model to Describe Bending Mechanics of Polypyrrole (PPy) Actuators", 2005 IEEE/ASME Int. Conference on Advanced Intelligent Mechatronics, pp. 1029 - 1034, Monterey, USA, July 2005.

[4] S. W. John, and G. Alici, "Towards micro and nano manipulation systems: behaviour of a laminated polypyrrole (PPy) actuator driving a rigid link", 2005 IEEE/ASME Int. Conf. on Advanced Intelligent Mechatronics, pp. 54 - 59, Monterey, USA, July 2005.

[5] G. Alici, and N. N. Huynh, "Predicting force output of trilayer polymer actuators", Sensors and Actuators A, 2006. Volume 132, No.2, pp. 616 625, November 2006.

[6] G. Alici, and N. N. Huynh, "Performance Quantification of Conducting Polymer Actuators for Real Applications: A Microgripping System", IEEE/ASME Trans. on Mechatronics, 12(1), pp. 73-84, February 2007.

[7] Y. Wu, G. Alici, G.M. Spinks and G.G. Wallace, "Fast tri layer polypyrrole bending actuators for high speed applications", Volume: 156, Issues 16-17, Synthetic Metals, pp. 1017-1022, August 1, 2006.

[8] W. Takashima, T. Uesugi, M. Fukui, M. Kaneko, and K. Kaneto, "Mechanochemoelectrical Effect of Polyaniline Film", Synthetic Metals, Volume 85, pp. 1395 - 1396, 1997.

[9] Y. Wu, G. Alici, J. M. D. Madden, G.M. Spinks and G.G. Wallace, "Soft Mechanical Sensors through Reverse Actuation in Polypyrrole", Advanced Functional Materials, 2007. (In print)

[10] J.D. Madden, "Conducting Polymer Actuators", PhD thesis, Massachusetts Institute of Technology, 2000.

[11] L. Ljung and T. Glad, Modeling of Dynamic Systems, Prentice Hall, USA, (1994). 